\section{Andit Commission's review of mental health services}

Sir: Renshaw (Psychiatric Bulletin, 1994, 18, 421-422) describes visits by the Audit Commission to mental health service providers and purchasers. Working in one of the 12 districts visited, we draw your attention to issues not covered by Dr Renshaw.

The "broad classification of need" does not stand up to close examination: it is described as "based on diagnosis and history of service use", but the category of need crucially depends on the number and duration of hospital admissions. Consequently a community orientated service (such as our own) will appear to have fewer high need patients than a service which still relies largely on hospital admissions.

Despite the stated emphasis on "value for money", the Audit Commission's work appears focused on process, with little or no emphasis on outcome measures. This makes comparisons such as "you have the highest number of community psychiatric nurses in London" meaningless in themselves. However they could well not be taken as meaningless by poverty stricken purchasers anxious to cut costs.

We cannot speak for the other services audited but we found the Audit Commission reluctant to take on board such comments nor would they correct errors such as counting a rehabilitation ward in the tally of acute beds, and counting CPNs' primary care caseload in with their workload for the psychiatric team to which they are attached.

Fiona Sim, Lester SIRELING, and George IKkOS, Barnet Psychiatric Unit, Barnet General Hospital, Barnet, Herts EN4 3DJ

Sir: We welcome the chance to address the issues raised by Drs Sim. Sireling, and Ikkos about the Audit Commission's review of mental health services.

One of our primary aims was to examine the extent to which secondary services were meeting the needs of people with severe mental illness in the community. The classification of need we used to examine the caseloads of community professionals was based on research carried out by Patmore \& Weaver (1991). According to the criteria, our categories A and B include anyone with a psychotic diagnosis or who has ever experienced hospital admission for a mental health problem. They therefore do not reply "crucially" on the number and duration of hospital admissions. The criteria were agreed with our advisory group, which included a nominee from the Royal College of Psychiatrists and four other eminent psychiatrists.

Our focus is on the process of care, since we feel that this is the area in which we can make a distinctive contribution. There is a good deal of work underway on outcome measures for mental health care, particularly the Health of the Nation Outcome Scales, but little is known nationally about the use of community services and hospital beds. We believe that our report has made a real contribution to this knowledge. Neither the report nor the local audits which will follow it make comments on the level of staffing or services avallable without placing them in the context of local need and the way in which the services are operating.

We dispute strongly the contention that we were unwilling to take comments on board or to correct 'errors'. The criteria to be used in the local audits have been extended, after discussion with professionals in Barnet and elsewhere, to provide more information on people with less serious mental health problems who are in touch with the secondary services.

We disagreed with the trust over the number of acute beds; however, the area of contention was not a rehabilitation ward, but an acute ward which was staffed at night and transferred patients to a day hospital during the day. These would be included as acute beds in Department of Health statistics, and we classified them in the same way to ensure that our figures could be compared with those avallable nationally. Finally, one of our major concerns was that community psychiatric nurses in Barnet were spending a large proportion of their time working in primary care, and this issue has also been raised nationally in a Department of Health review (Gournay \& Brooking, 1991). It would therefore have been wholly inappropriate to exclude this part of their caseload from our overall analysis.

GoURNAY, K. \& BRookns, A. (1991) A prospecture randomised controlled trial of the efficacy of CPNs and GPs in treating patients with minor psychiatic disorder in primary care. Middlesex Polytechnic. 
PATMORE, C. \& WraVER, T. (1991) Community Mental Health Teams: Lessons for planners and managers. Good Practices in Mental Health.

Judy Renshaw and Caroline Gardner, Audit Commission, 1 Vincent Square, London SWIP 2PN

\section{Poychiatry and war}

Sir: Dr Mezey's report on working with the victims of rape in Bosnia clearly portrayed the tragic effects of war on human health (Psychiatric Bulletin, 1994, 18, 696-698). War is undoubtedly the major cause of homicide.

The aetiology of war is complex. From a global perspective it represents the most extreme act of self-destruction with a morbidity many times worse than smoking. It arises in specific areas; in March 1994 the UN had 17 peacekeeping operations underway at an annual cost of $\$ 3.2$ billion; there have been 33 such operations since 1948 (United Nations Department of Public Information, 1994).

The mental set of populations and dominant forms of communication have been documented (Kosuta, 1993). The social manifestations associated with this are divided societies and high economic competition with neighbours. Historical injustice seems to occupy the collective unconscious. The awful scenario of increasing populations and decreasing resources beckons in the next century; this we know is a precursor of war.

As individual doctors we can work professionally on these issues and join organisations to debate and raise these issues at a political level. There is a need to expand the concept of public mental health to include this complex problem of human behaviour and perhaps the College has a role here. Where such agendas might be usefully discussed by the profession requires consideration.

KosutA, M. (1993) Media and the war in Croatla. Medictne and War, 9, 134-140.

UNITED NATONS DEPARTMENT OF PUBUC INFORMATION (1994).

J. PIACHAUd, Learning Disability Services, St Charles' Hospital, London W10 6DZ

\section{Attitudes of general practitioners and child peychiatrists to treatment methods}

Sir: I read Theodore Mutale's methodologically sound paper on the attitudes of general practitioners and child psychiatrists to treatment methods (Psychiatric Bulletin, 1994, 18, 668-669) with interest. I fear it may be a case of the Emperor's new clothes. Although general practitioners now have purchasing power, if the relevant therapies that they choose or prefer are of unproven value for particular conditions then surely this indicates a fallure of education and possibly a structural failure to encourage adequate research. Surely the central issue is what treatments are being used for which syndromes and whether these are (a) effective, (b) available and (c) what deleterious effects they may have.

DAVID KURL, Department of Child \& Adolescent Psychiatry, The Thelma Golding Centre, Hounslow TW3 3EL 